\title{
IN VITRO ANTICOAGULANT AND ANTIOXIDANT ACTIVITIES OF PRASAPLAI RECIPE AND ZINGIBER CASSUMUNAR ROXB. EXTRACTS
}

\author{
SURIYAN SUKATI ${ }^{1}$, KHEMJIRA JARMKOM ${ }^{2}$, SURACHAI TECHAOEI ${ }^{2}$, NAKUNTWALAI WISIDSRI ${ }^{2}$, \\ WARACHATE KHOBJAI ${ }^{2 *}$
}

${ }^{1}$ Department of Medical Technology, School of Allied Health Sciences, Walailak University, Nakhon Si Thammarat, Thailand. ${ }^{2}$ Department of Thai Traditional Medicine, Thai Traditional Medicine College, Rajamangala University of Technology Thanyaburi, Pathum Thani, Thailand. Email: warachate_k@rmutt.ac.th

Received: 14 November 2018, Received and Accepted: 12 December 2018

ABSTRACT

Objective: This present study aimed to evaluate the anticoagulant activity and antioxidant properties of Prasaplai recipe (PPR), a Thai traditional medicine, and its major ingredient, Zingiber cassumunar (ZC) Roxb. extracts, seeking new therapeutic purposes for the recipe.

Methods: Aqueous extracts of PPR and ZC Roxb. were prepared by hot water decoction technique. The anticoagulant activity of the extracts was evaluated by prothrombin time (PT) and activated partial thromboplastin time (APTT) tests. In addition to anticoagulant activity, total phenol content and antioxidant activity were investigated. Total phenol content was determined using the Folin-Ciocalteu assay. The antioxidant activity was estimated by DPPH radical scavenging activity and ferric reducing antioxidant power assay.

Results: The APTT of plasma samples mixed with the PPR and ZC Roxb. extracts was significantly prolonged $(\mathrm{p}<0.05)$ at the concentration of $1.0 \mathrm{mg} / \mathrm{ml}$ and above comparing to the control (normal saline solution) but was no significantly different for the PT. These results suggested that PPR and ZC Roxb. extracts showed anticoagulant activity affecting the function of coagulation factor in the intrinsic pathway. All aqueous extracts possessed considerable antioxidant activity and were rich in total polyphenol.

Conclusion: This finding indicates that the aqueous extracts possess significant anticoagulant and antioxidant activities, thus showing the potential PPR and ZC Roxb. as a new source of bioactive compounds for therapeutic purposes, with particular emphasis on the prevention and treatment of thrombosis.

Keywords: Prasaplai, Zingiber cassumunar Roxb., Coagulation, Antioxidant, Total phenol content, Thrombosis.

(C) 2019 The Authors. Published by Innovare Academic Sciences Pvt Ltd. This is an open access article under the CC BY license (http://creativecommons. org/licenses/by/4. 0/) DOI: http://dx.doi.org/10.22159/ijap.2019.v11s5.T0034

\section{INTRODUCTION}

Thai traditional herbal medicines are used for the treatment of various symptoms and diseases [1]. Buddhism believes that imbalance in one of four elements; earth, water, wind, and fire, within the human body could lead to illness. Zingiber cassumunar (ZC) Roxb. known as Plai, is one of the Thai herbal formulas which is used for restoring body elemental balance [2]. It is used for the treatment of menstrual disorders, flow enhancement of the discarded uterine blood after birth, wound healing, muscle and joint pain, skin diseases, inflammation, and abscesses [3]. ZC Roxb. is a major component of the Prasaplai recipe, a Thai traditional medicine formula, which has been used to relieve pain from the primary dysmenorrhea, regulates irregular menstrual flow, and driving out the discarded uterine blood after birth [2,4]. Prasaplai recipe has been listed in the Thai traditional common household drug list since 2006 [5]. To reduce pain, $1000 \mathrm{mg}$ orally 3 times a day before meals is recommended. This method is approved by the National Drug List of Herbal Medicinal Products AD 2008 [4]. The previous in vitro studies reported that Prasaplai recipe (PPR) acts as COX inhibitors which can help diminish pain from the primary dysmenorrheal [6].

Thrombosis is the condition of blood clot formation inside a vein or artery vessel that blocks the blood flow. If it slips from the vessel wall, it could obstruct in the organs causing heart and vascular diseases such as ischemic heart disease [7] and cerebrovascular disease [8]. A blood clot forms when there is an imbalance in the blood coagulation system, leading to several serious health conditions, for instance, venous thromboembolism which can cause deep vein thrombosis and/ or pulmonary embolism [9]. The treatment for blood clot embolism involves antiplatelet, anticoagulant, or thrombolytic medications. Anticoagulants, heparin, and warfarin are the main medications given for the prevention of blood clotting, whereas thrombolytic agents such as streptokinase dissolve the clot [9].

The previous studies have suggested that the consumption of antioxidant-rich foods might be important in preventing oxidative stress-induced platelet activation and aggregation, resulting in attenuating adverse hemostatic function [10]. Nowadays, therefore, much effort has been focused on natural products including medicinal plants, fruits, and vegetables, as antithrombotic agents [11]. The main reasons for using natural products are that they usually have less side effects on the body and comprise multiple constituents which each may have multiple targets increasing the therapeutic efficacy [12].

As their Thai traditional medicinal properties, including regulating irregular menstrual flow and enhancing the discarded uterine blood flow after birth, Prasaplai recipe and ZC Roxb. may affect the coagulation mechanism. Therefore, the present study was carried out aiming to evaluate their anticoagulant activity and antioxidant properties.

\section{MATERIALS AND METHODS}

\section{Plant materials}

Plant materials were purchased from a traditional herb market at Pathum Thani Province, Thailand. PPR was prepared from 12 components including $50 \%$ of the rhizomes powder of ZC Roxb. (81 parts), each eight parts of Citrus hystrix DC. (peel), Acorus calamus L. (root), Allium sativum L. (bulb), Eleutherine americana Merr. (bulb), 
Piper nigrum L. (fruit), Piper retrofractum Vahl. (fruit), Zingiber officinale Roxb. (rhizome), Curcuma zedoaria Roscoe. (rhizome), and Nigella sativa L. (seed), and two chemical compounds which are sodium chloride (8 parts) and camphor (1 part) [13].

\section{Extraction of plant material}

The extractions were performed by decoction technique, using boiling with distilled water [14]. The powder portion of PPR or ZC Roxb. $(10 \% \mathrm{w} / \mathrm{v})$ was soaked in boiling distilled water for $30 \mathrm{~min}$ at room temperature with occasional stirring. The solution was filtrated through Whatman'filter"paper No.1 and was then concentrated by lyophilization. The crude extracts of PPR and ZC Roxb. were kept in desiccators until used. For testing of anticoagulant activity in blood samples, the prothrombin time (PT) and activated partial thromboplastin time (APTT) tests were employed.

\section{Blood samples}

Peripheral blood samples were collected from 10 healthy human volunteers (five males and five females, aged 19-35 years). Volunteers had no history of oral contraceptive or anticoagulant therapy. The blood placed separately in containers containing $3.2 \%$ sodium citrate. Centrifugation was carried out at $1000 \times \mathrm{g}$ for $20 \mathrm{~min}$ at $4^{\circ} \mathrm{C}$, to separate the blood cells from plasma to obtain platelet-poor plasma (PPP). The PPP was employed for PT and APTT tests. The study design and informed consent form for the volunteers were approved by the Committee on Human Rights Related to Human the Experimentation of Western University, Kanchanaburi 70170, Thailand (reference number WTU2557-00172).

\section{PT and APTT testing}

To determine the extrinsic and intrinsic coagulant activity, the PPP was mixedwitheachextractsolution $(0.5-4.0 \mathrm{mg} / \mathrm{ml})$ ataratioof $1: 1 \mathrm{v} / \mathrm{v}[15] . \mathrm{PT}$ and APTT were determined in the mixtures by Neoplastine ${ }^{\circledR} \mathrm{CI}$ Plus and C.K. Prest ${ }^{\circledR}$ reagents (Diagnostica Stago S.A.S., France), respectively, according to manufacturer's instructions using the URIT-600 Coagulation analyzer (URIT Medical Electronic Co. Ltd., China). Normal saline solution (NSS) $(0.85 \% \mathrm{w} / \mathrm{v} \mathrm{NaCl}$, NSS) was used for the negative control. PT and APTT results are expressed in second (s). International normalized ratios (INRs) of PT were also determined.

$$
\text { PT } / \text { INR }=\left[\frac{\text { PT sample }}{\text { PT control }}\right]^{\text {ISI }}
$$

Where, ISI=International sensitivity index (1.28) Normal INR=0.9-1.2.

\section{Total phenolic content determination}

Total phenolic content was determined using a Folin-Ciocalteu method [16]. About $100 \mu \mathrm{l}$ of 1:10 Folin-Ciocalteu reagent dilution and $10 \mu \mathrm{l}$ of the sample were added into 96-well microplate. The microplate was incubated at room temperature for $7 \mathrm{~min}$. About $80 \mu \mathrm{l}$ of $1.0 \mathrm{M}$ $\mathrm{Na}_{2} \mathrm{CO}_{3}$ was added and then the solution was left at room temperature for $2 \mathrm{~h}$. The absorbance was measured at $750 \mathrm{~nm}$ using a microplate reader (Glomax-Multi Detection System, USA). The total phenolic content of the extract was calculated with a linear regression equation obtained from the gallic acid standard curve. Results were expressed as $\mathrm{mg}$ of gallic acid equivalent/g extract.

\section{DPPH radical scavenging activity}

The DPPH free radical scavenging was measured [17]. The $0.2 \mathrm{mM}$ solution of DPPH in methanol was prepared and $100 \mu \mathrm{l}$ of this solution was added to $100 \mu \mathrm{l}$ of ZC Roxb., Prasaplai, and a reference compound, ascorbic acid. After $30 \mathrm{~min}$, absorbance was measured at $520 \mathrm{~nm}$ using a microplate reader (Glomax-Multi Detection System, USA). All tests were performed in triplicate. The percentage of inhibition was determined by comparing the absorbance values of control and extracts.

$\%$ DPPH inhibition $=\frac{\text { A control }- \text { A sample }}{\text { A control }} \times 100$

\section{Ferric reducing antioxidant power (FRAP) assay}

The assay based on the reduction of ferric-tripyridyltriazine ( $\left.\mathrm{Fe}^{3+}-\mathrm{TPTZ}\right)$ to a blue-colored ferrous tripyridyltriazine ( $\mathrm{Fe}^{2+}-\mathrm{TPTZ}$ ) [18]. The $20 \mu \mathrm{l}$ of the extract was added to $150 \mu \mathrm{l}$ of the FRAP reagent and then incubated at $37^{\circ} \mathrm{C}$ for $4 \mathrm{~min}$. The absorbance of solutions was measured at $600 \mathrm{~nm}$ using a microplate reader (Glomax-Multi Detection System, USA). With $1 \mathrm{mM} \mathrm{FeSO}{ }_{4}$ solution as standard, FRAP value of the sample was expressed as $\mu \mathrm{M}$, using linear calibration obtained with the different concentration of $\mathrm{FeSO}_{4}$

\section{Statistical analysis}

The data obtained were analyzed using GraphPad Prism 6 version 6.01 (GraphPad Software Inc. La Jolla, CA, USA). All values are expressed as mean \pm standard deviation for three replicates. Data were analyzed by the one-way analysis of variance and the statistically significant differences were analyzed using a paired sample t-test. Value of $\mathrm{p}<0.05$ was considered to be statistically significant.

\section{RESULTS AND DISCUSSION}

\section{Anticoagulant activity}

The in vitro anticoagulant activity of the crude extracts of PPR and ZC Roxb. was evaluated by PT and APTT assays using pooled normal human plasma. The crude extract of PPR was evaluated for anticoagulant activity at the concentrations of $0.5,1.0,2.0$, and $4.0 \mathrm{mg} / \mathrm{m} 1$ while the extract of ZC Roxb. was determined for anticoagulant activity at the selected concentration, $1.0 \mathrm{mg} / \mathrm{ml}$ (Table 1). The APTT and PT baseline values of pooled plasma were $34.87 \pm 0.45$ and $11.80 \pm 0.17$ s, respectively. The APTT and PT values of NSS vehicle control were $41.70 \pm 1.13$ and $17.37 \pm 0.40 \mathrm{~s}$, respectively. The effect of the extracts on the APTT and PT testing was measured to evaluate anticoagulant activity against the extrinsic and intrinsic coagulation pathways. The PT results showed that PPR extract at concentrations of $0.5,1.0,2.0$, and $4.0 \mathrm{mg} / \mathrm{ml}$ was $18.23 \pm 0.45,17.57 \pm 0.31,17.40 \pm 0.10$, and $17.90 \pm 0.10$ s, respectively, while ZC Roxb. at the concentration of $1.0 \mathrm{mg} / \mathrm{ml}$ was $18.10 \pm 0.52 \mathrm{~s}$. The PT obtained in the presence of all concentration of the extracts was not significantly different $(p>0.05)$ when compared to NSS control (Fig. 1). The APTT of PPR extracts at concentrations of $0.5,1.0,2.0$, and $4.0 \mathrm{mg} / \mathrm{ml}$ was $44.93 \pm 2.19,45.87 \pm 0.70,47.53 \pm 1.57$, and $48.23 \pm 1.38 \mathrm{~s}$, respectively, while ZC Roxb. extract $(1.0 \mathrm{mg} / \mathrm{ml})$ was $50.17 \pm 1.11 \mathrm{~s}$. PPR at concentration of 1.0 to $4.0 \mathrm{mg} / \mathrm{ml}$ and ZC Roxb. $(1.0 \mathrm{mg} / \mathrm{ml})$ showed a highly significant difference compared to NSS control (Fig. 2). PT and APTT values of PPR at concentration of $0.5 \mathrm{mg} / \mathrm{ml}$ did not show a significant difference when compared to NSS control $(p>0.05)$ as shown in Table 1.

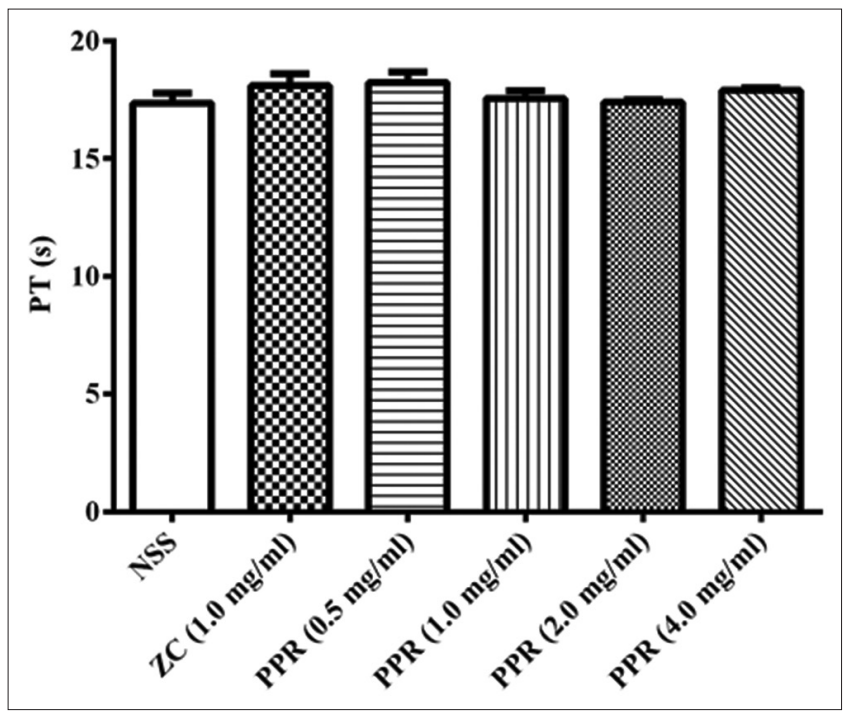

Fig. 1: Effect of PPR and ZC Roxb. extracts on prothrombin time compared with NSS. NSS: Normal saline solution, ZC: Zingiber cassumunar Roxb. (Plai), PPR: Prasaplai recipe 
The coagulation system involves a complex set of reactions involving many different proteins [19]. These reactions convert fibrinogen to fibrin, which forms a thrombus with platelets. The initiation of coagulation cascades is divided into two parts, intrinsic and extrinsic coagulation pathways. The extrinsic coagulation pathway is responsible for the initial generation of activated factor X (Factor Xa), which is induced by the factor VIIa/tissue factor complex. The intrinsic pathway composes of coagulation factors XII, XI, IX, and VIII. The activation of the intrinsic pathway leads to amplification of factor $\mathrm{Xa}$, which plays a central role in the coagulation cascade, called the common pathway [19]. The APTT and PT tests evaluate the ability to produce a blood clot in a reasonable amount of time and, if any of these factors are inhibited, the test results will be prolonged. The APTT evaluates coagulation factors VIII, IX, XI, and XII in the intrinsic coagulation pathway while the PT test is employed to evaluate the extrinsic clotting factors including coagulation factor VII. Moreover, these two tests also evaluate a common pathway involving factors I, II, V, and X of the clotting cascade. From our study, ZC Roxb. and PPR extracts were able to prolong APTT in a concentration-dependent manner, demonstrating its anticoagulant activity. In the PT test, no prolongation of the clotting time was observed. The prolongation of APTT, but not PT, indicates the inhibition of coagulation factor in the intrinsic coagulation pathway [20]. The present results suggest that ZC Roxb. and PPR inhibit preferentially intrinsic pathways of coagulation. The anticoagulant activity of the extracts against factors VIII, IX, XI, or XII was suspected. Since both PPR

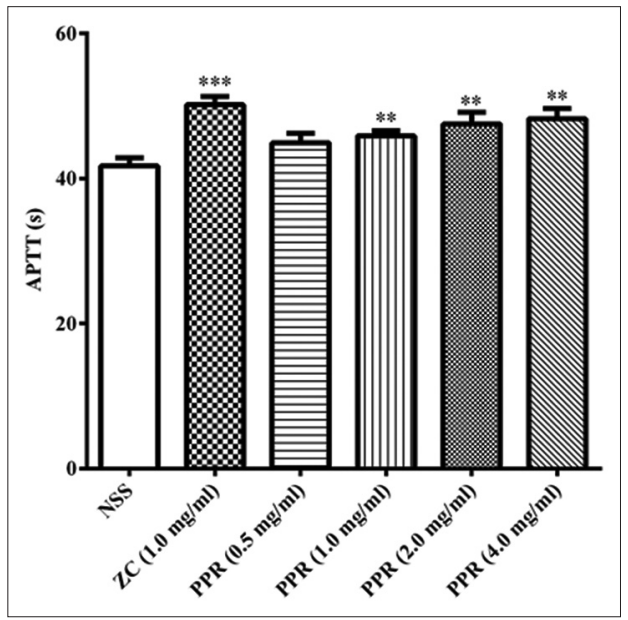

Fig. 2: Effect of Prasaplai recipe and ZC Roxb. extracts on activated partial thromboplastin time, ${ }^{* *} \mathbf{p}<0.01, * * * \mathbf{p}<0.001$, compared with NSS. NSS: Normal saline solution, ZC: Zingiber cassumunar Roxb. (Plai), PPR: Prasaplai recipe and ZC Roxb. exhibited anticoagulation activity through inhibition of coagulation factor in the intrinsic coagulation pathway, anticoagulant properties of PPR could be the active compound derived from ZC Roxb. which is the major ingredient of the formula. Phytochemical investigations of $\mathrm{ZC}$ Roxb. rhizomes have revealed the presence of $\alpha$-pinene, $\beta$-pinene, sabinene, $\gamma$-terpinene, terpine-4-ol [21], (E)-1- $(3,4$ dimethoxyphenyl) butadiene [22], naphthoquinones, phenylbutanoids, cyclohexene derivatives, vanillic acid, vanillin, veratric acid, terpenoids, curcuminoids, and $\beta$-sitosterol [23]. However, there are no direct studies of anticoagulation properties in individual compounds. The antithrombolytic activities of other components of Prasaplai formula have been reported. A. sativum L. suppresses the coagulation system by downregulating thrombin formation. Moreover, increased levels of thrombin-antithrombin III (TAT) complex, which induced by $A$. sativum L., can cause the prolongation of both PT and APTT tests [24]. In this study, however, the prolongation of PT was not detected in normal plasma which was treated with the aqueous extract of PPR. This could be probably explained by either the low concentration of active compound from the minor proportion of A. sativum L. in the PPR or the extraction method was used cannot properly extract the active compound from the recipe. In agreement with our results, some herbs, for instance, the aqueous extract of Jatropha gossypifolia L. showed anticoagulant activity against intrinsic coagulation pathway at the range of concentrations of $0.5-2.0 \mathrm{mg} / \mathrm{ml}$ [25]. Besides, the aqueous extracts from both PPR and ZC Roxb. revealed anticoagulant activity, our previous study showed that the extracts exhibited moderate thrombolytic activity [26]. Therefore, PPR and ZC Roxb. could potential antithrombotic properties. On the other hand, these results suggest avoiding the use of PPR and ZC Roxb. in patients who are considered to be high risk for bleeding.

\section{Total phenol content}

The total phenolic content of the extracts is shown in Table 2. These results demonstrated that total phenol content in the aqueous solvent of ZC Roxb. and PPR was uniform. There are evidence of positive association between total phenol content and the antioxidant properties. Gorinstein et al. [27] and Hodzic et al. [28] showed strong correlations between total phenolic content and antioxidant activity. They also demonstrated that the amount of total phenolic content could affect the antioxidant capacity. Their results displayed linear correlation between the amount of total phenolic content and antioxidant capacity where high total phenol content provides high antioxidant capacity.

\section{DPPH free radical scavenging activity}

DPPH radical scavenging activity by antioxidant is attributable to their hydrogen donating activity. The results showed that the percentage inhibition of $1 \mathrm{mg} / \mathrm{ml}$ of the aqueous extract of Prasaplai extract had a higher DPPH radical scavenging activity than ZC Roxb. extract (Table 2).

Table 1: Anticoagulant activities of ZC Roxb. and PPR extracts

\begin{tabular}{lllll}
\hline Sample & APTT $^{\text {a }}(\mathbf{s})$ & p-value & PT $^{\text {a }}$ (s) & p-value \\
\hline Baseline & $34.87 \pm 0.45$ & - & $11.80 \pm 0.17$ & - \\
NSS & $41.70 \pm 1.13$ & - & $17.37 \pm 0.40$ & - \\
ZC $1.0 \mathrm{mg} / \mathrm{ml}$ & $50.17 \pm 1.11$ & $0.0007^{* * *}$ & $18.10 \pm 0.52$ & - \\
PPR $0.5 \mathrm{mg} / \mathrm{ml}$ & $44.93 \pm 2.19$ & 0.0857 & $18.23 \pm 0.45$ & 0.1259 \\
PPR $1.0 \mathrm{mg} / \mathrm{ml}$ & $45.87 \pm 0.70$ & $0.0056^{* *}$ & $17.57 \pm 0.31$ & 0.0683 \\
PPR $2.0 \mathrm{mg} / \mathrm{ml}$ & $47.53 \pm 1.57$ & $0.0064^{* *}$ & $17.40 \pm 0.10$ & 0.5317 \\
PPR $4.0 \mathrm{mg} / \mathrm{ml}$ & $48.23 \pm 1.38$ & $0.0031^{* *}$ & $17.90 \pm 0.10$ & 0.8964 \\
\hline
\end{tabular}

${ }^{a}$ mean \pm SD, $* *$ p $<0.01, * * * p<0.001$, compared with NSS, ZC: Zingiber cassumunar Roxb. (Plai), NSS: Normal saline solution, PPR: Prasaplai recipe, APTT: Activated partial thromboplastin time

Table 2: Total phenolic content, DPPH inhibition, and FRAP values of Prasaplai recipe and Zingiber cassumunar Roxb. extracts

\begin{tabular}{llll}
\hline Plant & Total phenolic content ${ }^{\mathrm{a}}$ (mg GAE/g extract) & DPPH inhibition $^{\mathrm{a}} \boldsymbol{( \% )}$ & FRAP value $^{\mathrm{a}}(\boldsymbol{\mu} \mathrm{M})$ \\
\hline Prasaplai recipe & $43.93 \pm 0.42$ & $77.14 \pm 0.36$ & $1,032.38 \pm 2.21$ \\
Zingiber cassumunar Roxb. & $42.00 \pm 0.45$ & $73.11 \pm 3.80$ & $990.46 \pm 2.46$ \\
\hline
\end{tabular}

${ }^{a}$ All data were expressed in mean $\pm S D(n=3)$. GAE: Gallic acid equivalent, FRAP: Ferric reducing antioxidant power 
The DPPH radical scavenging activity was significantly positively correlated $(p<0.001)$ with the total phenolic content. The results were in agreement with the previous research results from Wu et al. [29] and Yang et al. [30].

\section{FRAP value}

The FRAP value of aqueous extract of ZC Roxb. and PPR was significantly different $(p=0.02)$, and the FRAP value of Prasaplai extract was higher than ZC Roxb. extract. ZC Roxb. extract has FRAP value of $990.46 \pm 2.46 \mu \mathrm{M} / \mathrm{g}$ sample and the Prasaplai extract with $1032.38 \pm 2.21 \mu \mathrm{M} / \mathrm{g}$ sample (Table 2). Based on reducing ferric ion in FRAP assay, higher FRAP value could reflect higher antioxidant activity [31]. Moreover, there was a positive correlation between the antioxidant activity and the total phenolic content in ZC Roxb. and PPR. This may indicate that the phenols in ZC Roxb. played an important role in antioxidant activity.

As the positive correlation between the antioxidant activity and the total phenolic content was observed in the extracts from PPR and its main ingredient, ZC Roxb., this may indicate that the phenols play an important role in antioxidant activity. Antioxidants are compounds that can donate single electron for reduction and consequently terminate the attack of free radicals, resulting in prevention of cell and tissue damage [32]. There are many factors affecting the extraction of antioxidant compounds from plants. The solvent used is an important factor to extract antioxidant compounds in plant materials due to their different polarity characteristics [33]. Therefore, different methods of extraction or other solvents such as methanol, ethanol, and acetone should be considered for PPR and ZC Roxb. extraction. Moreover, quality of extracts and antioxidant activities are also depend on geographic origin, harvesting season, and storage conditions [33].

\section{CONCLUSION}

We have described the in vitro anticoagulant activity of aqueous extracts from PPR and ZC Roxb., which are beneficial in Thai traditional medicine. Both extracts dose-dependently prolonged the APTT, suggesting that the extracts exhibit anticoagulant activity correlating with the intrinsic coagulation pathway. In addition to the anticoagulant activity, the extracts also proved to be a good source of antioxidant compounds. Since compounds with anticoagulant and antioxidant could be used for antithrombotic treatment, we suggest that based on our results, the aqueous extract of PPR and ZC Roxb. shows promising potential as a future therapeutic agent. Further work has to been done for isolation, characterization, and mechanism of action of the active phytochemical constituents from the herb, to establish an effective drug resource for prevention and treatment of disease caused by thrombosis.

\section{ACKNOWLEDGMENTS}

The authors would like to thank the financial support (Grant no. NRF04115804) from Thai traditional medicine college, Rajamangala University of Technology Thanyaburi, and the financial support (Grant no. WU60307) from Walailak University, Nakhon Si Thammarat, Thailand.

\section{CONFLICTS OF INTEREST}

All authors have none to declare.

\section{REFERENCES}

1. Subcharoen P. Thai traditional medicine in the new millennium. J Med Assoc Thai 2004;87 Suppl 4:S52-7.

2. Vannabhum $M$, Poopong $S$, Wongwananuruk $T$, Nimmannit $A$, Suwannatrai U, Dangrat C, et al. The efficacy of Thai herbal prasaplai formula for treatment of primary dysmenorrhea: A short-term randomized controlled trial. Evid Based Complement Alternat Med 2016;2016:2096797.

3. Farnsworth NR, Bunyapraphatsara N. Thai Medicinal Plants: Recommended for Primary Health Care System. Bangkok: Medicinal Plant Information Center; 1992.

4. Department for Development of Thai Traditional and Alternative
Medicine. List of Herbal Medicinal Product A.D 2008. Bangkok: Ministry Public Health; 2008.

5. Department for Development of Thai Traditional and Alternative Medicine. List of Herbal Medicinal Product A.D 2006. Bangkok: Ministry Public Health; 2006.

6. Lee W, Yoo H, Ku SK, Kim JA, Bae JS. Anticoagulant activities of piperlonguminine in vitro and in vivo. BMB Rep 2013;46:484-9.

7. Ambrose JA, Weinrauch M. Thrombosis in ischemic heart disease. Arch Intern Med 1996;156:1382-94.

8. Gorelick PB. Cerebrovascular disease. Pathophysiology and diagnosis. Nurs Clin North Am 1986;21:275-88

9. Waldo AL. Anticoagulation: Stroke prevention in patients with atrial fibrillation. Cardiol Clin 2009;27:125-35, ix.

10. Hubbard GP, Wolffram S, Lovegrove JA, Gibbins JM. The role of polyphenolic compounds in the diet as inhibitors of platelet function. Proc Nutr Soc 2003;62:469-78.

11. Slevin M, Ahmed N, Wang Q, McDowell G, Badimon L. Unique vascular protective properties of natural products: Supplements or future main-line drugs with significant anti-atherosclerotic potential? Vasc Cell 2012;4:9.

12. Fuentes E, Palomo I. Antiplatelet effects of natural bioactive compounds by multiple targets: Food and drug interactions. J Funct Foods 2014;6:73-81.

13. Gritsanapan W, Tangyuenyongwatana P. Standardization of prasaplai, a Thai traditional preparation for antidysmenorrhea. Botanics 2016;6:1-9.

14. Daswani PG, Ghadge AA, Brijesh S, Birdi TJ. Preparation of decoction of medicinal plants: A self-help measure? J Altern Complement Med 2011;17:1099-100.

15. Khan H, Khan MA, Mahmood T, Choudhary MI. Antimicrobial activities of Gloriosa superba Linn (Colchicaceae) extracts. J Enzyme Inhib Med Chem 2008;23:855-9.

16. John B, Sulaiman CT, George S, Reddy VR. Total phenolics and flavonoids in selected medicinal plants from Kerala. Int J Pharm Pharm Sci 2014;6:406-8.

17. Sanna D, Delogu G, Mulas M, Schirra M, Fadda A. Determination of free radical scavenging activity of plant extracts through DPPH assay: An EPR and UV-vis study. Food Anal Method 2012;5:759-66.

18. Rabeta MS, Faraniza RN. Total phenolic content and ferric reducing antioxidant power of the leaves and fruits of Garcinia atrovirdis and Cynometra cauliflora. Int Food Res J 2013;20:1691-6.

19. Palta S, Saroa R, Palta A. Overview of the coagulation system. Indian J Anaesth 2014;58:515-23.

20. Mao W, Li H, Li Y, Zhang H, Qi X, Sun H, et al. Chemical characteristic and anticoagulant activity of the sulfated polysaccharide isolated from Monostroma latissimum (Chlorophyta). Int J Biol Macromol 2009; $44: 70-4$

21. Casey TE, Dougan J, Matthews WS, Nabney J. Essential oil of "phlai" Zingiber cassumunar Roxb. from Thailand. Trop Sci 1971;13:199-202.

22. Tangyuenyongwatana P, Keeratinijakal V, Gritsanapani W. Thin-layer chromatography-densitometry analysis of dimethoxyphenylbutadiene content in Zingiber cassumunar rhizomes. J AOAC Int 2012;95:1614-7

23. Bhuiyan MN, Chowdhury JU, Begum J. Volatile constituents of essential oils isolated from leaf and rhizome of Zingiber cassumunar Roxb. Bangl J Pharmacol 2008;3:69-73.

24. Fukao H, Yoshida H, Tazawa Y, Hada T. Antithrombotic effects of odorless garlic powder both in vitro and in vivo. Biosci Biotechnol Biochem 2007:71:84-90.

25. Félix-Silva J, Souza T, Camara RB, Cabral B, Silva-Júnior AA, Rebecchi IM, et al. In vitro anticoagulant and antioxidant activities of Jatropha gossypiifolia L. (Euphorbiaceae) leaves aiming therapeutical applications. BMC Complement Altern Med 2014;14:405.

26. Khobjai W, Sukati S, Jarmkom K, Eakwaropas P, Techaoei S. Evaluation of thrombolytic activity of Zingiber cassumunar Roxb. and Thai herbal prasaplai formula. World Acad Sci Eng Technol Int J Med Health Biomed Bioeng Pharm Eng 2017:11:268-71.

27. Gorinstein S, Zachwieja Z, Katrich E, Pawelzik E, Haruenkit R, Trakhtenberg $\mathrm{S}$, et al. Comparison of the contents of the main antioxidant compounds and the antioxidant activity of white grapefruit and his new hybrid. LWT Food Sci Technol 2004;37:337-43.

28. Hodzic Z, Pasalic H, Memisevic A, Srabovic M, Saletovic M, Poljakovic M. The influence of the total phenols content on antioxidant capacity in the whole grain extracts. Eur J Sci Res 2009;28:471-7.

29. Wu LC, Hsu HW, Chen YC, Chiu CC, Lin YI, Ho JA. Antioxidant and antiproliferative activities of red pitaya. Food Chem 2006;95:319-27.

30. Yang D, Zhang Q, Ren G, Ying T. A comparative study on antioxidant activity of different parts of lotus (Nelumbo nuficera Gaertn) rhizome. 
Food Sci Technol (Campinas) 2007;37:135-7

31. Benzie IF, Strain JJ. The ferric reducing ability of plasma (FRAP) as a measure of "antioxidant power": The FRAP assay. Anal Biochem 1996;239:70-6.

32. Rice-Evans CA, Miller NJ, Paganga G. Structure-antioxidant activity relationships of flavonoids and phenolic acids. Free Radic Biol Med 1996;20:933-56

33. Moure A, Franco D, Sineiro J, Domínguez H, Núñez MJ, Lema JM. Antioxidant activity of extracts from Gevuina avellana and Rosa rubiginosa defatted seeds. Food Res Int 2001;34:103-9. 